\title{
3D FOREST FIRE PROPAGATION SIMULATION
}

\author{
Kıvanç Köse ${ }^{1}$, Nikolaos Grammalidis $^{2}$, Erdal Yllmaz, ${ }^{3}$, Enis Çetin $^{1}$ \\ ${ }^{1}$ Department of Electrical and Electronics Engineering, Bilkent University, \\ ${ }^{2}$ ITI-CERTH,${ }^{3}$ Informatics Institute, METU
}

\begin{abstract}
The increase in the number of forest fires in the last few years dispatch governments to take precautions. Besides prevention, early intervention is also very important in fire fighting. If the firefighters know where the fire will be in some time, it would be easier for them to stop the fire. Therefore a big need for simulating the fire behavior exists. In this paper we are proposing a system which can simulate the propagation of fire in time. Also this system can visualize the propagation of fire in any 3D-GIS environment, that accepts KMZ as a file format. Besides, any user demanded data can be visualized on the map of the system. This gives the chance of fire planning to firefighters. The system can visualize its results on $3 \mathrm{D}$ screens in 3D. Therefore, a better understanding of the terrain can be obtained.
\end{abstract}

Index Terms - Fire propagation, 3D fire visualization, forest fire, fire planning, fire fighting

\section{INTRODUCTION}

The effects of global warming become more and more visible in the last few years. Especially the increase in the number of the self-starting forest fires is a sign of this environmental threat. Therefore there is a great need for fire detection and propagation estimation. To watch the forest and forest fires, several fire posts are placed in the forests. Governments hire people and place them to those posts with the duty of watching the forest and informing the responders about any unusual event. Automation in this field is becoming an important issue in recent years. By only human power, it is impossible to survey vast areas of forests all the time. Therefore, several automatic systems are gradually replacing humans in this task.

For the above reasons, and since the level of maturity of the existing solutions is relatively low, fire detection and propagation prediction is an open research issue. Several European countries are making research in this area. In [1],[2] an automatic fire and smoke detection algorithm is given. Based on this algorithm, a new camera-based fire and smoke detec-

This work is supported by European Commission Sixth Framework Program with EU Grant: 511568 (3DT-TV NoE), and TUBITAK with project number: 105E191 - Video Based Outdoor Smoke and Fire Detection tion system is developed in Turkey, to replace the human factor in forest surveillance. By placing camera systems on the fire posts, the forests can be surveyed 24/7, and a forest fire can be detected within a few seconds after its ignition. The coordinates of fire can also be obtained through the system.

The Greek government has supported and is still supporting a number of projects aiming at the early prevention of forest fires, prediction of the fire propagation and providing support to decision makers. A system focusing on the provision of services for decision and operational support in forest fire suppression was implemented by the FIREMENTOR project [3], which has been recently completed. More specifically, FIREMENTOR consists of a state-of-the-art self-organizing fire sensor network along with a sophisticated software application, which offers to authorities and users a tool to create fire suppression scenarios, train professional and volunteer teams as well as the public, simulate and get prepared for extreme operational situations, and solve operational logistic problems. The system locates fire ignition points and supports the deployment of tactical forest fire suppression services in real time using a novel neural-network based expert system to estimate fire propagation.

In [4], a multidisciplinary system is proposed to provide rational and quantitative information based on the site-specific circumstances and the possible consequences and support decision makers during large-scale forest fire incidents. The systems architecture consists of several distinct supplementary modules of near real-time satellite monitoring and fire forecast using an integrated framework of satellite Remote Sensing, GIS, and RDBMS technologies equipped with interactive communication capabilities. This system can cope with multiple fire ignitions and support decisions regarding dispatching of utilities, equipment and personnel.

Although pilot implementations for both the above systems were deployed at Penteli mountain near Athens, the large fire in this mountain within 2007 showed that the problem still remains largely unsolved. Another problem is that the accuracy of novel fire propagation models can not be easily validated, except after a real fire incident, in which case the final outcome may be affected by many unpredictable factors (e.g. human intervention, local effects, etc.), which cannot be a-priori known or modeled.

The main motivation for this work is to simulate the prop- 
agation of the fire, which is detected by the system described in [1],[2]. By obtaining the ignition point of the fire, the proposed system can calculate where the fire is heading and how long will it take for the fire to reach to certain coordinate. The system can visualize the fire propagation on a 3D-GIS environment like Google Earth ${ }^{T M}$. The visualization is done in $3 \mathrm{D}$ so that a more realistic view of the fire propagation can be obtained.

The rest of this paper is organized as follows. In Section 2 the fire propagation simulator and its parameters are explained. Section 3 describes the approach for the computation of the geographical parameters and the visualization of results in both 2D and 3D. In Section 4, additional extensions are developed to display $3 \mathrm{D}$ visualizations on autostereoscopic displays as well as to create 3D animations of the fire propagation. In Section 5, conclusions are drawn and some future extensions of this work are discussed.

\section{WILDFIRE SIMULATION BASED ON FIRELIB LIBRARY}

Simulation of fire propagation is an important issue in forest fires. Predicting the fire propagation will give the information of when the fire will reach to a certain coordinate. It helps the firefighters to blockade the ways of fire, protect them from being trapped in fires, etc. Early intervention to threatened areas will increase the effectiveness of fire fighting. In [5], insight about some fundamental parameters of forest fires like, heat of combustion, extinction time, spread coefficients etc. Using those information several fire propagation algorithms and libraries were developed [6],[7].

In this work we are using the firelib [6] which is a $\mathrm{C}$ function library derived directly from the BEHAVE [7] for predicting fire propagation and intensity in two dimensions. The BEHAVE was developed by the U.S. Department of Agriculture Forest Service after mid 80s and it is widely used for predicting forest fire propagation.

In the following, we briefly describe the Firelib model parameters and discuss some modifications that we introduced, i.e. dynamic change of input (wind, moisture fuel type) and output (flame length) parameters. In order for the model to be efficient, forest fuels must be described in a particular way, in which the fuel characteristics are represented by certain average values. The set of these representative values is called a fuel model. Various researchers have developed such models for some of the most common fuel types in Greece. As an example, in [8], a small number of representative fuel models is defined for Greek forests, using statistical methods. In [9], a simple methodology for the development of such fuel models is presented, based on biomass estimation, specifically that of shrubs, using regression equations. In the future, we aim to define and use more suitable fuel models for the forests of Turkey and Greece as well as to define methods to estimate the required data for a particular region from different sources (e.g. specialized maps, satellite imagery, databases of forest authorities, etc.), to further improve fire modelling results.

In addition to the forest parameters, environmental parameters such as, the wind and the humidity of the weather, are also significantly affecting the fire behavior. Wind is a dominant factor in the prediction of the fire speed and its heading. In the absence of slope, fire propagates more rapidly in the direction of the wind. Humidity of the environment determines the humidity of the fuel, hence its flammability and consequently the fire spread rate. However besides the humidity of the weather at the time of fire, former humidity of the weather also affects the fire propagation. If the weather was humid or rainy in the last few days, the fuel would be wet. Therefore the ignitibility of the fuel decreases, which means that the propagation of the fire from one location to another is slowed down.

Besides the weather conditions, landscape is another very important parameter for the simulation. The slope and aspect are the most important parameters of the landscape. Fire propagates faster in the uphill and slowly in downhill directions. Aspect is important with respect to the interaction between the wind and the landscape. If the landscape is facing to the wind direction the effect of the wind on the fire increases.

After the values of all aforementioned parameters have been specified, the simulator can calculate the propagation of the fire on a landscape with varying conditions. Firelib is based on a orthogonal grid which divides the monitored region to a number of cells. To each of the cells specific parameter values like fuel type, fuel extinction ratio, aspect, slope, etc. are assigned. The parameters in a burning cell of Firelib are kept constant, in fact calculations for each cell are performed only once and for all, to yield an ignition time instant as well as an estimated flame length for the specific cell. However, as the fire goes from one cell to another, some of the parameters affecting the flame length may dynamically change (e.g. wind, moisture, fuel type), which is not currently taken into account by the Firelib model. To cope with this problem, we take into account the dynamically changing parameter values within the recursive computation of the ignition times. Furthermore, we have implemented a re-estimation of the flame length in all cells that have been already ignited. A future goal is to propose accurate and realistic models for the changes in BEHAVE fuel and moisture parameters with respect to time, after a cell has been ignited.

\begin{tabular}{ccc}
\multicolumn{2}{c}{ Heights of 3x3 Kernel Cells } \\
$h_{11}$ & $h_{12}$ & $h_{13}$ \\
$h_{21}$ & $h_{22}$ & $h_{23}$ \\
$h_{31}$ & $h_{32}$ & $h_{33}$
\end{tabular}

Table 1. Each cell has an $h$ which corresponds to its average height. $h$ values are derived from the $\mathrm{z}$ coordinates of the cells 


\section{CALCULATION OF SURFACE PARAMETERS AND VISUALIZATION OF RESULTS}

Slope, height and aspect are used as parameters in the fire propagation calculations. Therefore an efficient method to calculate those variables is needed. For this reason, we developed a method that uses Digital Terrain Model (DTM) to calculate these parameters, in order to have flexibility in the calculation. We calculated slope and aspect by using $3 \times 3$ kernel (Table 1), which covers center cell and surrounding eight cells. In this kernel we calculated north/south and east/west gradients as;

$$
\begin{aligned}
& d E W / d z=\left[\left(h_{13}+2 . h_{23}+h_{33}\right)-\left(h_{31}+2 . h_{21}+h_{11}\right)\right] / 8 . d x, \\
& d N S / d z=\left[\left(h_{11}+2 . h_{12}+h_{13}\right)-\left(h_{31}+2 . h_{32}+h_{33}\right)\right] / 8 . d y,
\end{aligned}
$$

where $x$ is the east to west cell width and $y$ is the north to south cell height. Using gradient formulas $(1,2)$ aspect and slope are derived as;

$$
\begin{gathered}
\text { Slope }=\operatorname{atan}\left[\left(\frac{d E W}{d z}\right)^{2}+\left(\frac{d N S}{d z}\right)^{2}\right]^{1 / 2} \\
\text { Aspect }=\operatorname{atan}\left(\frac{d E W}{d N S}\right)
\end{gathered}
$$

In the future we are planning to make this application a web service. Therefore the huge height information data can be stored in a server and can be served to clients for different analysis.

We prepared a single DTM file, which covers the Aegean and the Mediterranean regions. While preparing DTM we used downloadable, free-use Shuttle Radar Topography Mission (SRTM) data, with 3 seconds intervals. Using this DTM and our software, we can then query the slope, height and aspect information of any point using its longitude and latitude.

After calculating the fire propagation using Firelib, the resulting data should be visualized on a 3D-GIS environment. The raw propagation data, do not give any insight to the firefighters to decide on where to intervene the fire. By this $3 \mathrm{D}$ visualization, a better understanding of the fire propagation can be obtained. A software is developed to convert the fire propagation information to KMZ files. KMZ is an XML based geographical data serving file format that is used to visualize information on GoogleEarth ${ }^{T M}$.

Due to its layered structure, any data can be visualized on GoogleEarth $^{T M}$ independently of each other. For instance in Figure 1 an example visualization of the fire propagation is illustrated using color coding: red and its tones show the areas which will burn first, while blue and its tones show the areas which will burn later. This comprises the propagation layer. Another layer can be used to provide the exact ignition times, as shown in Figure 2. Other layers like those showing forest roads, fountains, etc. can also be defined and visualized independently. Another advantage of using GoogleEarth ${ }^{T M}$ is that the user can tilt and pan the viewing angle; thus allowing user interaction and enhancing the 3D feeling of the visualization (Figure 1). Also as seen in Figure 1 the slope, height and aspect information on the map be better visualized by this way.

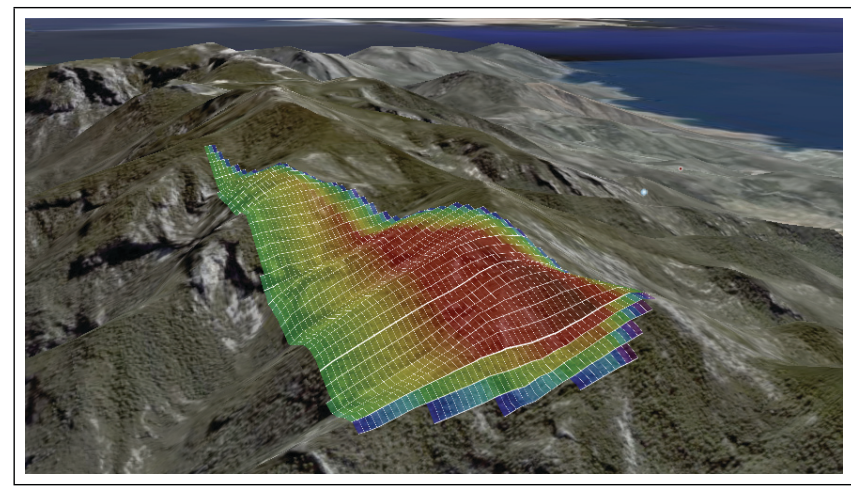

Fig. 1. Ignition times using color coding: red and its tones show the areas which will burn first, while blue and its tones show the areas which will burn later

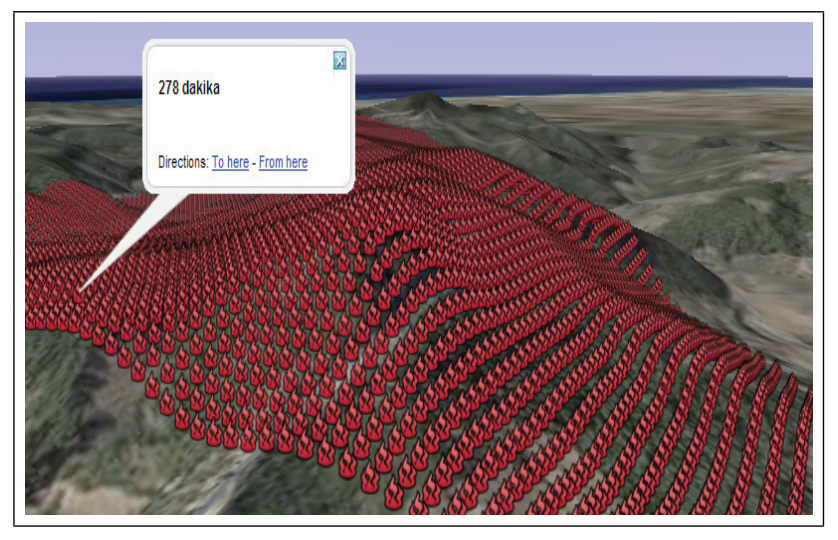

Fig. 2. Time information of fire visualized with flames. The time information can be reached by clicking on the flame on the respective area

\section{EXTENDED VISUALIZATION RESULTS}

Using GoogleEarth ${ }^{T M}$ we created a visualization for the fire propagation simulation results. New features of GoogleEarth ${ }^{T M}$ now enables us to visualize any geographical and logistical information on the 3D-GIS environment. Using this information, firefighters can plan their movements and actions to confront the fire.

Besides the GIS functionality of GoogleEarth ${ }^{T M}$ we also tried to use an innovative visualization by rendering above mentioned outputs in Sharp Actius ${ }^{T M}$ autostereoscopic notebook. By the help of Tridef TM Visualizer [10] plug-in, it is now possible to view GoogleEarth ${ }^{T M}$ scenes in real-time $3 \mathrm{D}$. We observed that this is quite interesting when we use 3D bars such as flame maps (Figure 3). Also as a future work we 
consider to use this functionality to render trees and other 3D features such as power-lines etc. in the fire area.

Besides the static representation, we can also create an animation of the flame propagation. Using the propagation and time information, the propagation can be visualized as an animation. Some frames of the animation are provided in Figure 4. Also the flame length information is embedded in the animation so that a more realistic $3 \mathrm{D}$ animation of the fire propagation is created.

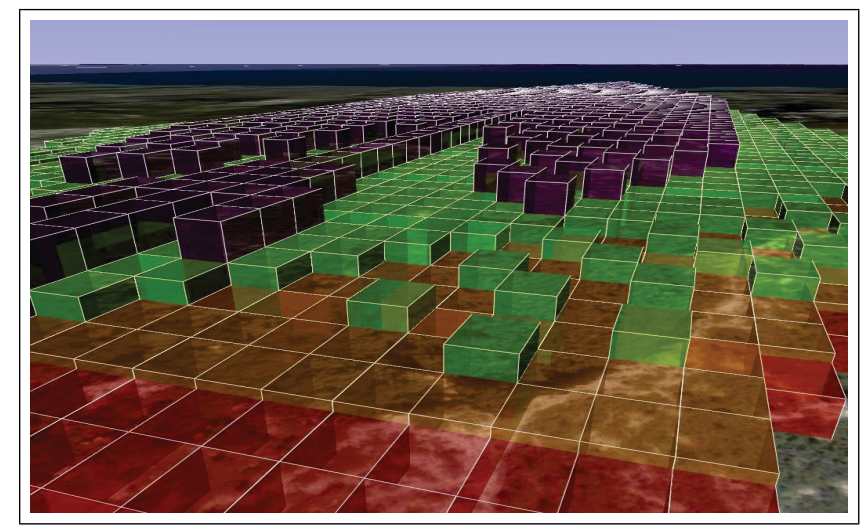

Fig. 3. Flame length information is also shown in frames of propagation animation. This type of animation can be visualized on Sharp Actius ${ }^{T M}$ autostereoscopic notebook in 3D.

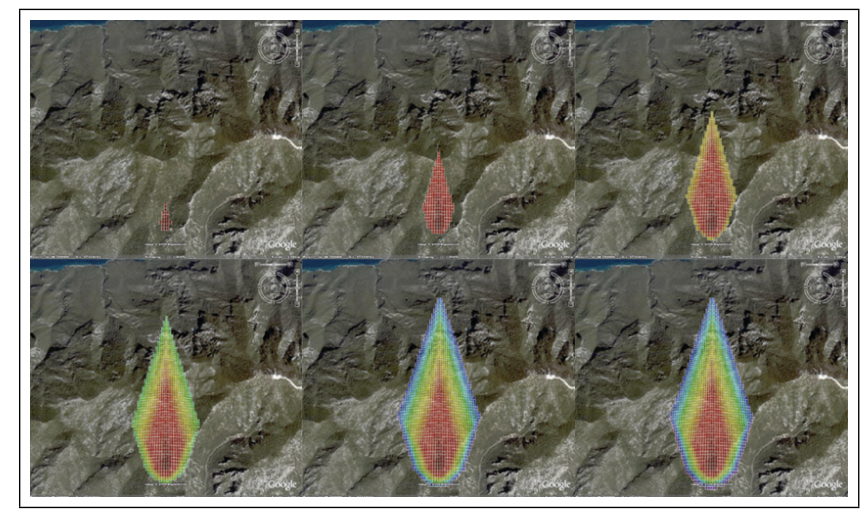

Fig. 4. Animation of fire propagation is composed of several frames showing the propagation at different times.

\section{CONCLUSION AND FUTURE WORK}

The proposed system can produce realistic simulations using the geographical information at a given region. The results of these simulations are statically or dynamically visualized on GoogleEarth ${ }^{T M}$. Features of GoogleEarth ${ }^{T M}$ eg. zooming, tilting, panning, offer the user a better view of the site and the fire progress. Also now we can place logistical information on GoogleEarth ${ }^{T M}$ so that fire site planning can also be done using our software. Moreover if the user has a PC with support for autostereoscopic display, he/she can visualize everything in $3 \mathrm{D}$. This is a totally new approach in fire propagation simulation.
There are some issues that we should deal with in the future. The most important one is the deriving the fuel models of Turkey and Greece. For now we used the most appropriate model among the 13 already defined models in Firelib. But we are planning to derive more accurate forest models of Turkey and Greece.Another future issue is to obtain the wind information in real time. Wind information obtained from meteorology or devices on the fire posts can not be precise enough and offers limited resolution for our simulations. Therefore, we are planning to develop an algorithm to estimate wind speed from the videos of the fire sites.

\section{REFERENCES}

[1] Toreyin, B. U., Dedeoglu, Y., Gudukbay, U., Cetin, A. E., "Computer Vision Based System for Real-Time Fire and Flame Detection", Pattern Recognition Letters, Vol.27 pp. 49-58, (2006)

[2] Toreyin, B. U., Dedeoglu, Y., Cetin, A. E., "Wavelet Based Real-Time Smoke Detection in Video", $13^{\text {th }} \mathrm{Eu}$ ropean Signal Processing Conference - EUSIPCO 2005.

[3] Firementor project, Greek National Project, http://www.firementor.gr/english.htm

[4] Keramitsoglou, I., Kiranoudis, C.T., Sarimvels H. et al., 2004.A multidisciplinary decision support system for forest fire crisis management. Environmental Management, Vol.33, No.2, pp.212 - 225.

[5] Rohermel, R. C., "A Mathematical Model for Predicting Fire Spread in Wildland Fires", USDA Forest Service General Technical Report INT-115, Ogden, UT, 1972.

[6] Firelib software implementation and documentation, http://www.fire.org/index.php?option=content\&task= category\&sectionid $=2 \& \mathrm{id}=11 \&$ Itemid $=29$

[7] Andrews, P. L., "Behave: Fire Behavior Prediction and Fuel Modeling System - BURN Subsystem Part 1", USDA Forest Service General Technical Report INT194, 1986.

[8] Dimitrakopoulos, A. P., G. Xanthopoulos, and V. Mateeva, "Statistical Classification of Mediterranean Fuel Types in Greece", Proc. of the International Symposium on Forest Fires: Needs and Innovations, pp. 125-131, November, 1999.

[9] Xanthopoulos, G., Manasi, M., "A Practical Methodology for the Development of Shrub Fuel Models for Fire Behavior Prediction", Forest Fire Research and Wildland Fire Safety: Proc. of IV International Conference on Forest Fire Researc, Wildland Fire Safety Summit, Luso, Coimbra, Portugal, pp. 18-23 November, 2002.

[10] http://www.tridef.com/display/profile/all.html 